\title{
Die Evangelien und die Apostelgeschichte
}

\author{
Studien zu ihrer Theologie und zu ihrer Geschichte
}

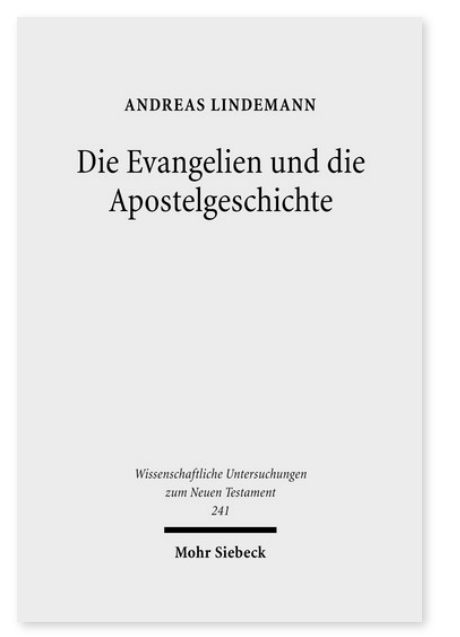

2009. VIII, 422 Seiten. WUNT I 241

ISBN 978-3-16-151530-9

DOI 10.1628/978-3-16-151530-9

eBook PDF $144,00 €$

ISBN 978-3-16-150041-1

Leinen $144,00 €$
Andreas Lindemann versammelt 16 exegetisch-theologische Aufsätze zu den Evangelien und zur Apostelgeschichte, die während seiner Forschungs- und Lehrtätigkeit an der Kirchlichen Hochschule Bethel entstanden.

Im ersten Kapitel legt er wichtige Texte des Markusevangeliums aus. Im zweiten Kapitel geht es um Grundfragen der Auslegung der Logienquelle Q, um parallele Reden und Erzählungen im Lukasevangelium und in der Apostelgeschichte, um das Bild der Anfänge des christlichen Lebens in Jerusalem und der Anfänge der »Heidenmission«. Die Studien zum Johannesevangelium im dritten Kapitel fragen nach dem Verhältnis der Gemeinde zur »Welt« und nach dem Verständnis des Gesetzes. Im vierten Kapitel werden übergreifende Themen der Theologie und Hermeneutik erörtert, so zur Frage einer »Theologie der synoptischen Evangelien« zu neueren Tendenzen in der Auslegung neutestamentlicher Wundererzählungen und zum Jesusbild der Evangelien, insbesondere im Blick auf Jesu Verhältnis zu Menschen aus der Völkerwelt. Jedes Kapitel wird mit einem Überblick über Aspekte der neueren Forschung eingeleitet.

Andreas Lindemann Geboren 1943 in Leer (Ostfriesland); Studium der Ev. Theologie in Tübingen und Göttingen; 1975 Promotion; 1977 Habilitation; 1978-2009 Professor für Neues Testament an der Kirchlichen Hochschule Bethel; seit 2009 im Ruhestand; seit 2008 korrespondierendes Mitglied der Akademie der Wissenschaften zu Göttingen.

Jetzt bestellen:

https://mohrsiebeck.com/buch/die-evangelien-und-die-apostelgeschichte-9783161515309?no_cache=1 order@mohrsiebeck.com

Telefon: +49 (0)7071-923-17

Telefax: $+49(0) 7071-51104$ 